\title{
Long term adaptation to electrically induced cycle training in severe spinal cord injured individuals
}

Thomas Mohr, Jesper L Andersen, Fin Biering-Sørensen, Henrik Galbo, Jens Bangsbo, Aase Wagner and Michael Kjaer

Copenhagen Muscle Research Centre and Centre for Spinal Cord Injured, The Neuroscience Centre, National University Hospital and Department of Medical Physiology, Panum Institute, University of Copenhagen, Copenhagen, Denmark

Spinal cord injured (SCI) individuals most often contract their injury at a young age and are deemed to a life of more or less physical inactivity. In addition to the primary implications of the SCI, severe SCI individuals are stigmatized by conditions related to their physically inactive lifestyle. It is unknown if these inactivity related conditions are potentially reversible and the aim of the present study was, therefore, to examine the effect of exercise on SCI individuals. Ten such individuals (six with tetraplegia and four with paraplegia; age 27-45 years; time since injury 3-23 years) were exercise trained for 1 year using an electrically induced computerized feedback controlled cycle ergometer. They trained for up to three times a week (mean 2.3 times), 30 min on each occasion. The gluteal, hamstring and quadriceps muscles were stimulated via electrodes placed on the skin over their motor points. During the first training bouts, a substantial variation in performance was seen between the subjects. A majority of them were capable of performing $30 \mathrm{~min}$ of exercise in the first bout; however, two individuals were only able to perform a few minutes of exercise. After training for 1 year all of the subjects were able to perform $30 \mathrm{~min}$ of continuous training and the work output had increased from $4 \pm 1($ mean $\pm \mathrm{SE})$ to $17 \pm 2$ Kilo Joules per training bout $(P<0.05)$. The maximal oxygen uptake during electrically induced exercise increased from $1.20 \pm 0.08$ litres per minute measured after a few weeks habituation to the exercise to $1.43 \pm 0.09$ litres per minute after training for 1 year $(P<0.05)$.

Magnetic resonance cross sectional images of the thigh were performed to estimate muscle mass and an increase of $12 \%$ (mean, $P<0.05$ ) was seen in response to 1 year of training. In biopsies taken before exercise various degrees of atrophy were observed in the individual muscle fibres, a phenomenon that was partially normalized in all subjects after training.

The fibre type distribution in skeletal muscles is known to shift towards type IIB fibres (fast twitch, fast fatiguable, glycolytic fibres) within the first 2 years after the spinal cord injury. The muscle in the present investigation contained of $63 \%$ myosin heavy chain (MHC) isoform IIB, $33 \% \mathrm{MHC}$ isoform IIA (fast twitch, fatigue resistant) and less than 5\% MHC isoform I (slow twitch) before training. A shift towards more fatigue resistant contractile proteins was found after 1 year of training. The percentage of $\mathrm{MHC}$ isoform IIA increased to $61 \%$ of all contractile protein and a corresponding decrease to $32 \%$ was seen in the fast fatiguable $\mathrm{MHC}$ isoform IIB, whereas MHC isoform I only comprised 7\% of the total amount of MHC. This shift was accompanied by a doubling of the enzymatic activity of citrate synthase, as an indicator of mitochondrial oxidative capacity.

It is concluded that inactivity-associated changes in exercise performance capacity and skeletal muscle occurring in SCI individuals after injury are reversible, even up to over 20 years after the injury. It follows that electrically induced exercise training of the paralysed limbs is an effective rehabilitation tool that should be offered to SCI individuals in the future.

Keywords: spinal cord injuries; tetraplegia; paraplegia; electrical muscle stimulation; exercise; skeletal muscle

\section{Introduction}

Spinal cord injury (SCI) is a catastrophic event. It often occurs within seconds and causes the most drastic

Correspondence: T Mohr

Dr Thomas Mohr received the Lars Sullivan Award 1996 for this article changes for an individual regarding physical status and lifestyle for the individuals remaining lifetime. These changes include impaired or abolished motor control and sensibility below the level of the lesion, loss of normal bladder and bowel function, disturbed sexual 
function and impaired function of the sympathetic nervous system. Before World War II, $80 \%$ of people suffering from SCI died within 1 year of the injury ${ }^{1}$ and the main causes of death were pulmonary infections, infections in the urogenital system and septicaemia caused by infections from pressure sores. Since then the possibilities to treat these infections have increased and a general awareness and understanding of the multidisciplinary problems of the SCI person has emerged. In consequence, the lifespan has increased, but is presently still lower than the average life expectancy of able-bodied persons. ${ }^{2}$

It must be noted that the majority of SCI happens in relatively young persons and therefore these individuals will live a major part of their lives after the injury. ${ }^{2-4}$ Generally, these individuals exhibit a substantial, if not total, loss of muscle control below the level of the spinal cord lesion and are therefore often unable to perform sufficient voluntary exercise in order to maintain a good level of physical fitness. In recent years there has been an increased awareness of the need for physical exercise in this population, since it has been demonstrated, that they suffer more from inactivity related diseases than does the background population. ${ }^{5}$ In the SCI population as well as in the able-bodied population one of the leading causes of death is cardiovascular disease. ${ }^{6,7}$ However, these diseases occur earlier in life in the SCI population than in the able-bodied. ${ }^{6}$ It has, in fact, been shown that the major disability in SCI individuals, next to the spinal cord injury itself, originates from diseases of the cardiovascular system. ${ }^{6}$ There is strong indirect evidence that the enhanced occurrence of cardiovascular disease in SCI individuals is related to reduced physical activity during daily living. 8,9 With this background, we found it important to investigate the reversibility with training of inactivity related changes in muscle and in maximal cardiopulmonary activation in individuals with SCI.

\section{Materials and methods}

\section{Subjects}

The study was approved by the Regional Ethics Committee of Copenhagen and Frederiksberg Municipalities. Ten SCI subjects were enrolled after oral and written information and they all signed an informed consent form. Prior to the study, none of the subjects had any experience with regular training using electrical stimulation. All were neurologically stable and there was a term of at least 2 years after the injury when entering the study. They all had a traumatic SCI, seven resulting from traffic accidents, two due to accidents during sporting activities and one from shallow water diving. Eight males and two females were included and the average age was 35.3 (range 27-45) years when entering the program. Time since injury was 12.5 (range $3-23$ ) years. Six had tetraplegia with the level of injury at C6 and the remaining had paraplegia, with the injury level at T4 (Table 1). The subjects reflected the distribution of gender and the level of the neurological lesion in the Danish spinal cord injured population. ${ }^{3}$ The two females were paraplegic. All of the subjects had no motor control of their lower extremities and all had complete sensory denervation except for one patient who had some skin sensation in the left gluteal region. Spasms were occasionally experienced by all of the subjects. No subject had diseases or disabilities other than the SCI and only one patient was periodically medicated with Ephedrine because of hypotension. No drugs were allowed on training days when special measurements or evaluations were performed as described below.

\section{Training equipment}

For training of the SCI subjects, a computer-controlled FES exercise ergometer (REGYS I Clinical Rehabilitation System, Therapeutic Alliances Inc., Ohio, USA) was used. This system has been described elsewhere, ${ }^{10-}$ 12 and only the following adjustments were made.

To avoid repetitive use of tape and plaster on the skin (Figure 1a), a pair of elastic biking tights was made for each individual. Pockets for the wires were sewn into the tights for each electrode (Figure 1b). When the subjects put on the tights at home, only the electrodes required to be placed prior to each training session.

To prevent upper body movements as much as possible and to give the subjects the best possible support of the upper body, we designed a handlebar for the subjects to lean on during the biking exercise. The handlebar consisted of a horizontal bar with a triathlon handlebar mounted on top. The subjects could then be supported and rest on the handlebar when leaning forwards. The handlebar could be moved forwards whilst the subject went in or out of the chair and moved back during exercise. It gave the needed support to all subjects and avoided the need for an uncomfortable belt around the chest.

Table 1 The subjects

\begin{tabular}{lcccc}
\hline No. & Gender & Age in years & $\begin{array}{c}\text { Level of } \\
\text { lesion }\end{array}$ & $\begin{array}{c}\text { Years since } \\
\text { injury }\end{array}$ \\
\hline 1 & M & 44 & T 4 & 19 \\
2 & M & 41 & C 6 & 20 \\
3 & M & 31 & C 6 & 7 \\
4 & M & 27 & C 6 & 3 \\
5 & M & 35 & C 6 & 8 \\
6 & M & 45 & T 4 & 11 \\
7 & F & 27 & T 4 & 14 \\
8 & F & 42 & T 4 & 23 \\
9 & M & 27 & C 6 & 13 \\
10 & M & 34 & C 6 & 11 \\
\hline
\end{tabular}


a

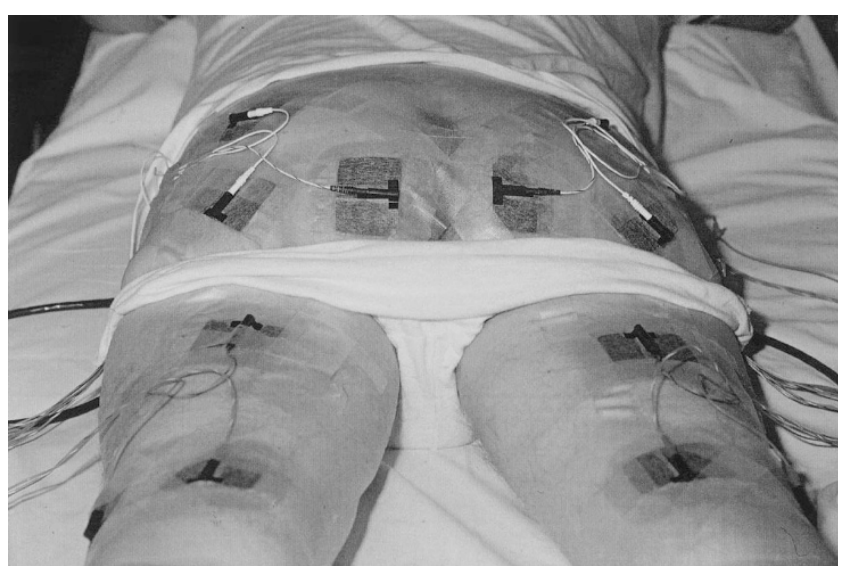

b

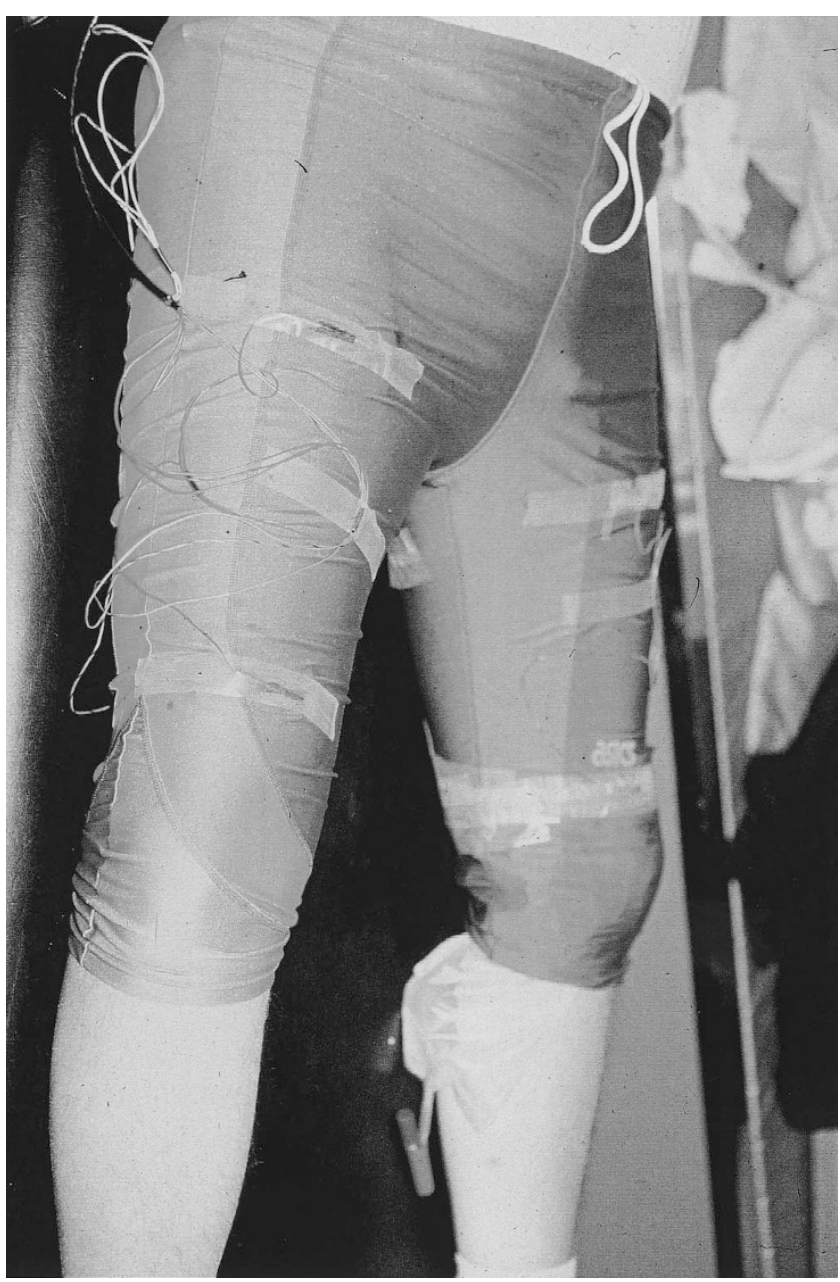

Figure 1 (a) The stimulation electrodes on the gluteal region and on the hamstrings. In the picture the electrodes were attached to the skin with tape. (b) However, to avoid the repeated use of tape on the skin, special cycle tights fixing the electrodes were developed for training

\section{Training protocol}

Each subject was scheduled to engage in one bout of exercise three times a week for 1 year. At most, a vacation for 3 consecutive weeks was allowed to make the training period as continuous as possible. All measurements in the training period were made after a period of at least 2 weeks of regular exercise with 3 attended sessions per week and more than 1 month after vacation periods.

When the subjects were able to perform $30 \mathrm{~min}$ of continuous exercise in one bout, load was added progressively to the fly-wheel of the ergometer in order to make the exercise as intense as possible. Load was added from $1 / 8 \mathrm{kp}$ up to $7 / 8 \mathrm{kp}$ as maximum. There was no rigid rule on progression. The highest possible resistance compatible with pedalling frequency of 50 revolutions per minute was added. Resistance was again reduced when the pedalling speed dropped below 50 revolutions per minute with maximal stimulation. The training outcome, ie the work intensity (in Watts) and the time cycled at the different levels of loading, were noted for each session and the total power output per session was calculated (in KJoules).

Measurement of maximal oxygen uptake ( $\mathrm{VO}_{2}$-max) When the subjects were accustomed to the exercise and able to perform more than $5 \mathrm{~min}$ of continuous exercise, the first measurement of $\mathrm{VO}_{2}$-max was performed. The load on the ergometer was increased gradually, according to knowledge of the performance of each individual subject, until fatigue occurred. The total time of the test was kept within $10 \mathrm{~min}$. The subjects tolerated increases in load differently, some attained the highest work output when a rapid load increase was applied whereas others needed very slow increases in order to attain their maximum performance before fatigue occurred. $\mathrm{VO}_{2}$ was continuously measured using an Ergo-Oxyscreen (Jaeger instruments) which had previously been tested to yield the same values as were obtained by collecting expired air in Douglas bags and analysing them with oxygen and carbon dioxide gas metres. ${ }^{13,14}$ The highest measured oxygen uptake in a period of approximately $2 \mathrm{~min}$ on the highest possible workload was considered $\mathrm{VO}_{2}$-max. When fatigue was reached, no passive pedalling was performed in contrast to what was done in the normal exercise sessions. One and $3 \mathrm{~min}$ after termination of exercise, capillary blood was sampled from a fingertip and the blood lactate concentration was analysed using an Analox PLU 5 enzymatic analyser.

\section{Thigh girth}

Thigh girth was measured 10 and $20 \mathrm{~cm}$ above the upper patellar edge before the start of the training and every second month during the training period. The measurement was performed in the supine position and always prior to exercise to avoid the influence of a possible exercise induced muscle swelling. ${ }^{15}$ 
Muscle cross sectional area

Before and after the period of 1 year of training, magnetic resonance imaging (MRI) was performed on the mid portion of the thigh. The magnet used was a 0.3 Tesla whole body magnet, and the images were kept on file until the end of the study for evaluation. The subjects were placed in the magnet and axial scout scans were performed from the knee to the pelvis in order to make the cross sections at exactly the same distance from the pubic bone at each scanning session. The scans were performed before the exercise to avoid acute effects of potential exercise induced muscle swelling.

At the end of the training period all the files were transformed from the optical disks (Fonar) and planimetry was performed using the NIH image system made and distributed by the National Institute of Health, USA. The cross sectional areas of the leg, the muscle tissue and the bone at mid thigh level were measured from the scans.

\section{Muscle biopsies}

Needle biopsies $(150-200 \mathrm{mg})$ were taken from the middle portion of the vastus lateralis muscle. ${ }^{16}$ Local anaesthetics (2 $\mathrm{ml}$ lidocain, $1 \%$ ) were administered subcutaneously prior to incision of the skin to avoid local acute reactions which could generate spasms during the procedure. The biopsy was divided in two portions. One portion was frozen immediately in liquid nitrogen for myosin heavy chain (MHC) analysis and for quantification of citrate synthase. The other part was mounted in Tissue-TEK, (Miles Inc., Elkhart, IN, USA) and frozen rapidly in isopentane, cooled to the temperature of liquid nitrogen for histological analysis. The samples were stored at $-80^{\circ} \mathrm{C}$ until analyzed.

\section{Muscular microstructure}

Serial sections $(10 \mu \mathrm{m})$ were cut at $-20^{\circ} \mathrm{C}$ in a cryostat, mounted on glass slides and subsequently stained according to the procedure described by Brooke and Kaiser. ${ }^{17}$ Sections were visualized and analyzed on a computer system (Tema 95, Scanbeam $\mathrm{a} / \mathrm{s}$, Hadsund, Denmark) using software designed to calculate the fibre areas. Fibres smaller than $200 \mu \mathrm{m}^{2}$ were not counted and were only present in a small number. The number of these small fibres varied between subjects and between biopsies from the same subject at different time points.

\section{Fibre types, myosin heavy chain (MHC) analysis on homogenates}

Gel-electrophoresis of muscle homogenates was used to differentiate between MHC isoforms. Twenty slices of $10 \mu \mathrm{m}$ were cut from the Tissue-TEK embedded biopsy and then denaturated by heating in a solution containing mercaptoethanol and sodium dodecyl sulphate (SDS) for $10 \mathrm{~min} .{ }^{18}$ The homogenates were loaded on SDS-PAGE (sodium dodecyl sulphate poly acryl amide gel electrophoresis) gels containing $37.5 \%$ glycerol and $6 \%$ polyacrylamide. Electrophoresis was performed for $18-20 \mathrm{~h}$ at $70 \mathrm{~V}$ followed by $3-5 \mathrm{~h}$ at 200 V. ${ }^{19}$ The gels were subsequently silver-stained (Gelcode color silver stain, Pierce). The relative proportions of the three distinct bands (MHC I, IIA and IIB) were analyzed on a computer-integrated densitometer (Cream 1-D, Kem-En-Tec Aps, Copenhagen, Denmark). The test-retest error on the densitometer was less than $5 \%$, when gels were analyzed 5 times.

\section{Activity of citrate synthase}

A part of the muscle biopsy frozen in liquid nitrogen was freeze dried, and connective tissue and fat tissue were removed under a stereo microscope. The activity of citrate synthase in these samples was measured flurometrically as described elsewhere. ${ }^{20}$

\section{Statistics}

Wilcoxon's non-parametric signed rank test was used for statistical comparison of values before and after training, unless otherwise stated. $P$ values less than 0.05 in two-tailed testing were considered significant for all measured parameters.

\section{Results and discussion}

\section{Exercise tolerance}

The participants in the study exhibited various degrees of exhaustion during the first bouts of exercise. All subjects stated that the first exercise was odd and compared the feeling of physical exhaustion after the exercise to the feeling they remembered from the time before their injury. They felt that the abnormal movements of their legs was strange, but none felt discomfort. Half of the subjects felt the urge to move the upper body synchronously during exercise while the other half enjoyed the movements of their legs and did not move their upper body at all. In three of the subjects post exercise hypotension was a problem after the first exercise bouts and they had to rest in the supine position in the chair for some minutes before they could tolerate movement back into their wheel chair. These subjects were often suffering from dizziness due to hypotension after moving from the supine to the sitting position, most pronounced in the morning. After the first 10 exercise bouts, they somehow adapted to the exercise and problems thereafter rarely occurred. Due to the potential occurrence of autonomic dysreflexia, the first exercise bouts were closely supervised by the medical staff. However, there were no instances of autonomic dysreflexia in any of the patients, neither during regular exercise nor during experimental procedures and to our knowledge there have been no reports of 
autonomic dysreflexia due to this kind of cycle exercise. As described earlier, the maximal current of the stimulation was preset to $130 \mathrm{~mA}$ to protect the tissue under the stimulation electrodes. This limit is likely to be far below the threshold of skin burns, since muscle stimulation with $300 \mathrm{~mA}$ has been given in one study with no harmful effects. ${ }^{21}$

Due to the lack of sensibility in the legs of the subjects, injuries due to overloading caused by high training progression are a potential risk, particularly in the first period of the training, since prior to training the only movement of their legs had (for years) been passive or caused by spasms. We only experienced one complication, in subject no. 7, who had a small haematoma in the medial portion of the quadriceps muscle, apparently due to a fibrillar tear after $15 \mathrm{~min}$ of exercise in her second exercise bout. She was treated with 1 week of rest and ultrasound every second day for 2 weeks and had no symptoms thereafter.

\section{Accomplished training sessions}

The average number of accomplished training sessions in the 1 year period was 2.3 times per week. The subjects were all scheduled for three times of training each week, but vacations, illness and practical problems (eg transport problems or cancellations of domestic caretaking for tetraplegic individuals) naturally gave rise to cancellations within this long period of training. However, an attendance frequency of more than $75 \%$ is very satisfactory and higher than what is typically seen in training programmes for patients less handicapped than SCI individuals.

Other investigators have reported the accomplished number of training sessions to be 2.7 per week out of a maximum of 3 . Furthermore, in these studies the subjects were followed for only 12 to 16 weeks. ${ }^{22,23}$ However, in another study using three weekly scheduled sessions for a total of 78 training sessions, the average number of sessions attended was found to be 46 , corresponding to only 1.8 times per week and thereby markedly lower than in the present study. ${ }^{24}$ No previous reports that we are aware of have been provided on training within SCI individuals for a period for as long as a year. In ablebodied elderly women the same rate of completed exercise bouts as in our study was seen in a longterm training study, in which a total of $79 \%$ of the exercise sessions (among those who completed the study) were accomplished in a 52 week study with high and low intensity training. ${ }^{25}$

\section{Progression in training duration}

In the first training sessions a vast variability in exercise endurance was found. Two subjects (no. 1 and 2) could perform pedalling for less than $1 \mathrm{~min}$ and were therefore allowed five stimulation bouts in each session, making the total exercise time only around
$3 \mathrm{~min}$ in the first sessions. In contrast, four subjects (no. 3,4,5 and 7) were able to pedal the ergometer continuously for $30 \mathrm{~min}$ in the first session. Most subjects were able to pedal continuously for $30 \mathrm{~min}$ within the first 3 weeks of training and after 3 weeks of cycling all but two individuals performed $30 \mathrm{~min}$ of cycling in one bout. The last two subjects (no. 1 and 2) did not adapt as quickly. For the subjects who were capable of exercise for only a few minutes each time, very little progression was observed over five to 10 training bouts. However, since only anecdotal information and no scientific data existed regarding any late adaptation in exercise performance, the training was continued (Figure 2). One subject (no. 1) had slow progress in exercise time, until he could perform $10-$ $15 \mathrm{~min}$ of exercise. Then he showed a rapid increase in exercise time, until he could perform 30 min of exercise after 14 weeks and after 18 weeks he could exercise against external resistance. The other subject (no.2) was only able to perform $12-17 \mathrm{~min}$ over the five bouts of exercise in each session for more than 6 months. But rather suddenly, after more than 10 months, he rapidly increased his training time and reached $30 \mathrm{~min}$ within the next 4 weeks of training. $\mathrm{He}$ remained able to pedal 30 min continuously for the rest of the period. However, only very little external resistance was tolerated.

Since the two slower adapting subjects were as much as 19 and 20 years beyond their injury, it could not be ruled out that an extremely long time of inactivity could be the cause of their slower adaptation to exercise training. However, the number of observations is small and arguing against this mechanism, another subject (no. 8) with even longer duration of injury was able to perform $30 \mathrm{~min}$ of exercise in the first training bout. Furthermore, in the present study no correlation between adaptation time and age or gender could be established and no direct

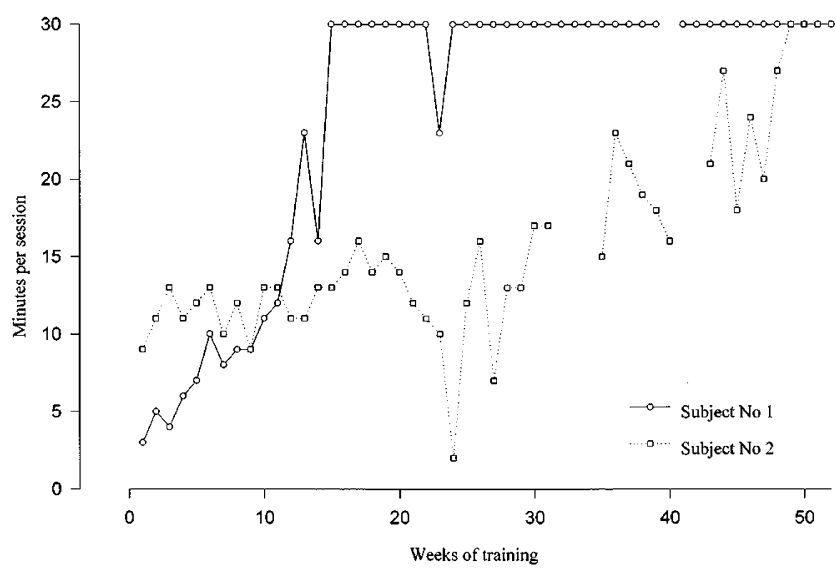

Figure 2 Progression in training time for the two individuals who were slowest to adapt during the 52 weeks of training. All other subjects were able to perform $30 \mathrm{~min}$ of continuous exercise within the first 3 weeks of training (not shown) 
explanation for the slow adaptors could be given from anamnestic information. It is of particular interest that their sudden abrupt increase after months of training could not be explained by any external cause. Of note is the fact that among all subjects studied, these two individuals had the most pronounced muscle atrophy as judged from histological sections (see muscle adaptation). This could, in part, explain their poor initial performance. Since the optimal stimulation frequency was variable from one individual to another (unpublished results) and from one muscle to another, another explanation could be that the optimal frequency for these slowly adapting subjects differed much from the frequency used in the study. In consequence, the two subjects might require a more profound adaptation (eg changes in fibre types) before exercise performance could be increased. Other investigators have not given detailed information as to the progression of the training until the subjects could exercise 30 min. ${ }^{22,23,26}$ One study, involving subjects with similar age and time since injury as in the present study, reported the mean time before the subjects could perform $30 \mathrm{~min}$ of cycling to be 3 months, ranging from 1 to 4 months. $^{26}$ This corresponds with the results from the present study.

In many FES cycle training studies, training has been initiated with a period of knee extension training, where only the quadriceps muscle was stimulated and exercised against increasing loads. This strength training was carried out for up to 12 weeks before cycle ergometry was initiated. ${ }^{23,24,26-29}$ The intention was to habituate the subjects to the electrically induced exercise and adapt the muscles to contractions by increasing strength and endurance. In contrast to the experience in the present study, Goss et $a l^{24}$ reported the knee extension exercise to be necessary, as the SCI individuals had minimal lower extremity strength and were unable to cycle at the onset of their study. Petrofsky et $a l^{29}$ reported that the average cycle endurance was only $8.3 \mathrm{~min}$ in the first cycle session with an external resistance of $0 \mathrm{Kp}$, despite the fact that the muscles had been pretrained by weightlifting for 4 to 6 weeks. Since most of the previous studies did not report major beneficial effects from the legextension exercise that could be transferred to the cycle exercise and since all the subjects in our study were able to perform some cycle exercise from the beginning, specific knee extension exercises were not carried out. For the subjects, one of the advantages of the cycling exercise was the positive memory of this exercise pattern from their life before the injury. Furthermore, motivation was low in all subjects for leg-extension training. Finally, the intensive isolated quadriceps training in a totally untrained SCI individual could cause muscular imbalance over the involved joints and biomechanical imbalance might be a disadvantage when electrically induced cycling exercise should follow a period of quadriceps strength training.
Total work output

Load was tolerated in all subjects after a number of training sessions. The average tolerated load per session is given in Figure 3. In the Figure, the average work output is calculated over 4 week periods. From an average of $3 \mathrm{~kJ}$ per week in the first 4 week period the power output increased significantly to $9 \mathrm{~kJ}$ in the following 4 week period $(P<0.05)$. Within 6 months of training, the power output increased to $15 \mathrm{~kJ}$ per session, then the increase in performance levelled off and very little changes occurred in the following 6 months. The peak power output achieved during the training period ranged from $4 \mathrm{~kJ}$ per session in the weakest subject (no. 2) to $50 \mathrm{~kJ}$ in the strongest (no. 5). The weakest subject was one of the before mentioned slow adapting subjects and the resistance he tolerated never exceeded $1 / 8 \mathrm{KP}(6 \mathrm{~W})$. In contrast, the strongest individual could tolerate $7 / 8 \mathrm{kp}(42 \mathrm{~W})$ for up to $7 \mathrm{~min}$ in each training bout before the resistance had to be decreased in order to keep the pedalling frequency at 50 revolutions per minute. This target frequency was kept in all subjects, although in some the frequency decreased to 45 revolutions per minute during short periods (few min) of the exercise, due to heavy relative loading. Despite the use of maximal resistance in all training bouts, only a few of the subjects increased their maximal capacity in the last half year of the training period. At the end of the 1 year period, one subject cycled most of the time at $0 \mathrm{~W}$, three subjects at $6 \mathrm{~W}$, three at $12 \mathrm{~W}$ and three at $18 \mathrm{~W}$. The absence of increase in performed work output in the last 6 months of the training indicates that the subjects had achieved the maximum power output that was possible with the applied training regimen.

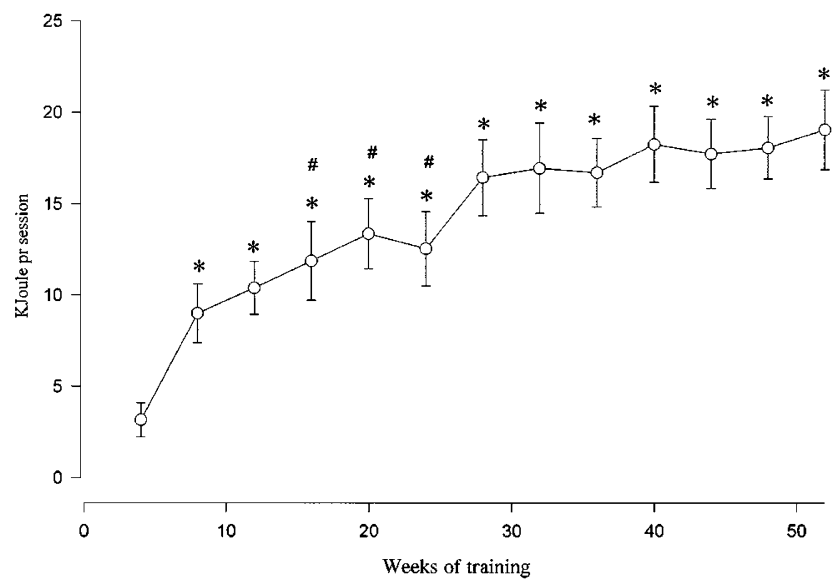

Figure 3 Work output per session. Calculated by integration of exercise intensity as a function of exercise duration. Average values $( \pm \mathrm{SE})$ determined over 4 weeks are shown. Note the plateau reached after 6 months of exercise. \#indicates differences from 12 weeks before, $P<0.05$ and *indicates differences from initial value, $P<0.05$ 
A power output of zero watt may not accurately reflect the actual increase in metabolic rate above basal and has to be taken with some caution. As with any ergometer the inertia of the flywheel was not zero and particularly in this setup a substantial resistance arose from the cushion in the seat, because the subjects could not use a normal bicycle saddle, due to the need for additional support from a wider seat. This support imposed a non-specified resistance from the repeated deformation of the cushion by the movements of the legs. In addition, the pattern of stimulation was far from physiological, because only few muscles were involved, because recruited fibres always contracted tetanically, because active fibres were stimulated throughout each contraction, and because the antagonist were within no control during the exercise. Efficiency of electrically induced movements relative to that of voluntary exercise has been found to be $1: 4$, by use of epidural anaesthesia and electrically induced cycling in able-bodied subjects. ${ }^{11}$ In line with these facts efficiency of electrically induced exercise in SCI individuals (calculated to approximately $4 \%$ ) is very low compared to that of voluntary exercise. ${ }^{29} \mathrm{It}$ follows that unloaded exercise with an ergometer power output of zero on the equipment we used should not necessarily be considered useless from a training perspective.

The increase in power output found in the present study corresponded to the increase observed in other studies. ${ }^{23,24,26}$ Arnold et $a l^{26}$ reported a resistance of $4 /$ 8 to $5 / 8 \mathrm{kp}$ to be tolerated after 6 months of training, but the duration of the exercise at that resistance was not given and therefore the total work output in a training session could not be calculated. Goss et $a l^{24}$ reported on five persons exercising between 6 and 12 $\mathrm{W}$ after 6 months of training, but whether this was tolerated during all $30 \mathrm{~min}$ of the training was not noted. Hooker et $a l^{23}$ gave information on the variation in power output after 36 sessions (12 weeks), one person cycling at $0 \mathrm{~W}$, two at $6 \mathrm{~W}$, six at $12 \mathrm{~W}$, four at $18 \mathrm{~W}$ and one at $30 \mathrm{~W}$. A similar variation was found in the present study after 6 months of training.

In two additional studies by Faghri et $a l^{22,30}$ a higher increase in power output was reported compared to the present study, although it cannot be stated if this difference is significant. A power output of $15 \mathrm{~W}$ for $15 \mathrm{~min}$ (corresponding to a total of $17 \mathrm{~kJ}$ ) was found after 36 sessions of training, even though the exercise time in each training bout was only $15 \mathrm{~min}^{22}$

The same group reported a power output of $17 \mathrm{~W}$ throughout $30 \mathrm{~min}$ (corresponding to a total of $31 \mathrm{~kJ}$ ) after 12 weeks of training with three times $30 \mathrm{~min}$ per week. ${ }^{22}$ The subject characteristics in the present study was different from those in the studies by Faghri ${ }^{22,30}$ who had a group of incompletely injured subjects with some remaining voluntary muscular function in their legs.

Noteworthy is the fact that none of the studies, including the present one, reported differences in the increases of power output over time in tetraplegic subjects versus those with paraplegia. ${ }^{22-24,30}$ Hence, the beneficial systemic effects from FES training are possibly more marked in tetraplegic subjects compared to those with paraplegia, because the latter can achieve greater benefit with voluntary training of their upper body compared to those who are tetraplegic.

\section{Changes in $\mathrm{VO}_{2}$-max}

The first measurement of peak oxygen uptake was performed when the subjects were habituated to the exercise and at least able to cycle continuously for $5 \mathrm{~min}$. This value, obtained after $5.8+1.0$ weeks (mean $\pm \mathrm{SE}$, range $2-8$ weeks) of training and denoted the zero value, was $1.20 \pm 0.08$ litres/min (mean $\pm \mathrm{SE}$ ). After training for 6 months the oxygen uptake had increased to $1.41 \pm 0.10$ litres $/ \mathrm{min}$ and after 12 months to $1.43 \pm 0.09$ litres $/ \mathrm{min}(P<0.05)$.

The highest value was obtained at different times in the various subjects and was for the whole group $1.48 \pm 0.10$ litre $/ \mathrm{min}$. It appears in the Figure 4 as Max. The increase from the initial value to 6 months was $18 \%$, whereas no further increase was seen from 6 to 12 months. The maximal increase was an average of $23 \%(P<0.05)$

In eight of the subjects included in the present study, the peak oxygen uptake during wheel chair exercise on a treadmill was $0.87 \pm 0.09$ litre $/ \mathrm{min}$

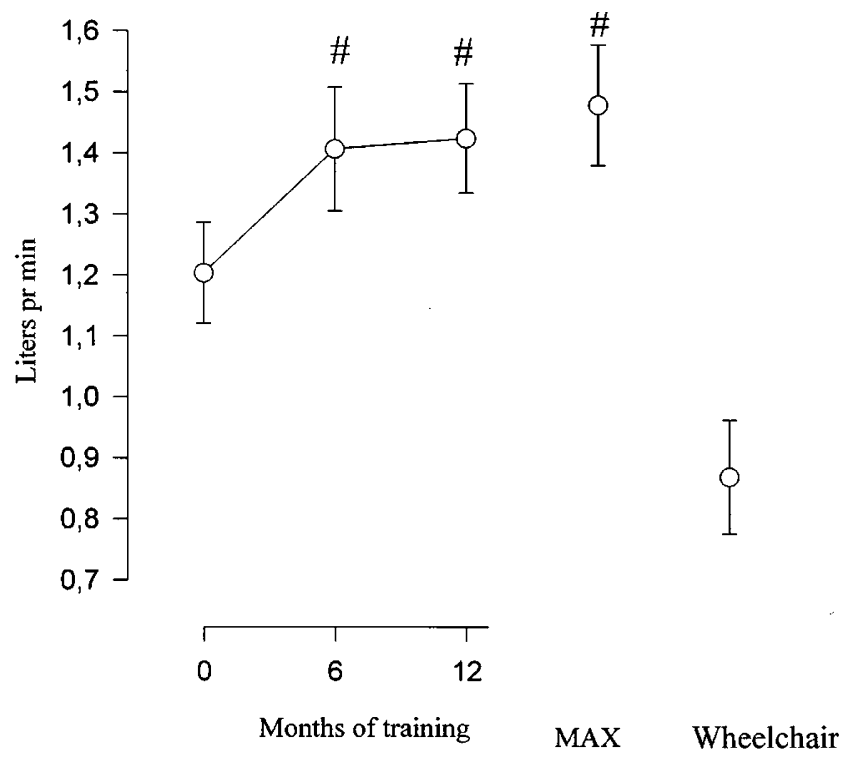

Figure 4 Maximal oxygen uptake. Measured after habituation to exercise (mean: 6 weeks), after 6 months and after 1 year of exercise. The highest values for the various subjects were not obtained at the same time points. This value is given as MAX in the figure. For comparison, the $\mathrm{VO}_{2} \max$ measured in eight of the ten subjects during wheelchair exercise on a treadmill is shown (Wheelchair). \# indicates differences from initial value, $P<0.05$ 
(mean $\pm \mathrm{SE}$ ) with no changes throughout the training period (personal communication, $\mathrm{S}$ Broberg and $\mathrm{K}$ Christophersen, Nat Soc of Polio and Accident Victims). This value was significantly lower $(P<0.05)$ than all measurements during electrically induced cycling and corresponded to $70 \%$ of the oxygen uptake in the initial test and to $56 \%$ of the highest values found during electrically induced cycling.

No differences were found in blood lactate values between one and $3 \mathrm{~min}$ after termination of an exercise test and no change was seen over the training period $(9.0 \pm 1.2$ and $11.8 \pm 0.9 \mathrm{mmol} / 1$ (mean $\pm \mathrm{SE})$ before and after the training period, respectively). The respiratory exchange ratio (RER) measured at the end of each test ranged from 0.9 to 1.3 in the various subjects, but was most often below 1.0.

The endpoint of a test evaluating maximal aerobic power in able-bodied subjects is often perceived exhaustion and the result is considered to represent the individual's maximal aerobic power, if the peak lactate after the test is $8 \mathrm{mM}$ or higher or if the RER is above $1.0{ }^{31}$ In SCI subjects the perceived strenuousness during electrically induced exercise is unreliable in the test situation as a measure of exhaustion, since the subjects have no sensibility in the exercising muscles and because the continuation of the exercise depends on the stimulation and the peripheral condition of their muscles. The peak blood lactate concentration after the tests was higher than $8 \mathrm{~mm}$. However, it has been shown that FES gives rise to higher increases in lactate than voluntary exercise in able-bodied individuals. $^{11}$

In healthy subjects the cardiac pump capacity limits $\mathrm{VO}_{2}$-max. If a small muscle mass is used, the maximal cardiac pump activity cannot be reached. ${ }^{31}$ Correspondingly, in SCI individuals the small muscle mass recruited by FES probably sets the limit for $\mathrm{VO}_{2}$-max. In other words, the $\mathrm{VO}_{2}$-max reflects the electrically activated muscle mass. Supporting this view an increase in $\mathrm{VO}_{2}$-max is seen when voluntary arm exercise is added to leg FES exercise in SCI individuals. $^{32}$ Also supporting the view that the amount of stimulated muscle is limiting the $\mathrm{VO}_{2}$-max in SCI individuals is a study in which a higher current (up to $300 \mathrm{~mA}$ ) was used during cycle exercise. ${ }^{21} \mathrm{~A}$ $34 \%$ higher $\mathrm{VO}_{2}$-max than during exercise with $130 \mathrm{~mA}$ was seen during cycle exercise with $300 \mathrm{~mA}$. However, not all subjects could tolerate this high current, although no injuries were reported. It appears that the measured $\mathrm{VO}_{2}$-max values in the present study are likely to reflect the recruitable peripheral oxidative capacity and, accordingly the amount of stimulated muscle mass, which is rather small and with little endurance capacity, especially in the beginning of the study.

The results show an increase in maximal oxygen uptake from the initial value to the value after 6 months, after which no further increase was seen (Figure 4). The duration of training was not increased during the period, but the intensity of the training was increased as much as tolerated throughout the period. The fact that a steady state level was attained in the last 6 months indicates that the amount of training performed has to be increased more than in the present study to gain further increase in peripheral oxidative capacity. Thus, the oxygen uptake we found will be the maximally obtainable when training is performed for $30 \mathrm{~min}$ for approximately three times per week and stimulation current is not increased beyond what we used. Another interpretation of the fact that the $\mathrm{VO}_{2}$-max plateaued during the last 6 months of training is that during this period the leg oxidative capacity exceeded the pumping capacity of the heart, which then became the limiting factor for the $\mathrm{VO}_{2}$-max, as in able-bodied subjects during bicycle exercise. ${ }^{31}$ Abnormal nervous innervation of the heart during FES exercise might explain that any training effect in the heart would be modest compared to that of the recruited muscles.

Other studies have measured oxygen uptake in response to electrically stimulated exercise, but only a few have reported changes due to repeated exercise, ie training, most of them only applying a short training period of 12 weeks. ${ }^{23,24,28,32}$ Pollack et $a l^{28}$ reported in 1989 a change in oxygen uptake in response to FES training from $0.53 \pm 0.07$ to $1.04 \pm 0.13$ litres $/$ min (mean $\pm \mathrm{SE}$ ). The training regimen consisted of 12 weeks of knee extension exercise, 12 weeks of cycle exercise without load added, followed by 12 weeks of cycle exercise with as much load added as the subjects tolerated. Even though the subjects characteristics were almost identical and the equipment used identical compared with the present study, the initial values in the study by Pollack et al were much lower than those noted in the present study. The measures made after the knee extension exercise and before the cycle training period were $0.65 \pm 0.11$ litres $/ \mathrm{min}$. In response to the 24 weeks of cycling exercise the oxygen uptake increased to $1.04 \pm 0.13$, an increase of $60 \%$, still far above the increase of $18 \%$ in the present study. The very low initial values in the study of Pollack et al could be explained by the absence of habituation to the cycle exercise and thereby lower values were measured. Furthermore, the test for $\mathrm{VO}_{2}$-max measurement using 3 min steps and $1 / 8 \mathrm{kp}$ increments could be inappropriate in the early tests when the subjects tolerated very little resistance and no steady state oxygen uptake was likely to be reached on the last step. An increment of $1 / 8 \mathrm{kp}$ was for our subjects a large increase and the equipment allowed smaller increases, although such increments were not registered on the computer.

Hooker et $a l^{23}$ trained a group of 18 tetra- and paraplegics comparable to our group over 36 sessions and found an increase in oxygen uptake from $0.78 \pm 0.01$ to $0.95 \pm 0.01 \mathrm{litre} / \mathrm{min}($ mean $\pm \mathrm{SE})$. The increment was $23 \%$ and accordingly similar to that seen in the present study after 6 months. The stress test protocol in the study by Hooker et $a l^{23}$ consisted of $5 \mathrm{~min}$ exercise bouts with $5 \mathrm{~min}$ rests between and 
the load was increased by $1 / 8 \mathrm{kp}$ after each rest period. Again, the stress test protocol could be responsible for the low initial values and hence for the large increase. Furthermore, it was not reported if a period of habituation had been allowed before the initial test. It should be noted that the initial $\mathrm{VO}_{2}$-max measurements in the present study were performed after nearly 6 weeks of training. The amount of training per week in the study of Hooker et $a l^{23}$ was similar to that of the present one, but the subjects were only trained for 3 months. It is likely that the changes seen in the present study after 6 months could have been demonstrated at an earlier time point, a view supported by the fact that some subjects achieved their $\mathrm{VO}_{2}$-max within the first 5 months. Goss et $a l^{24}$ reported in 1992 an increase in oxygen uptake from $0.79 \pm 0.23$ to $1.01 \pm 0.25$ litre $/ \mathrm{min}$, an increase of $27 \%$, after 6 months of training in five subjects. The initial measurements were in that study carried out when the subjects were able to perform $5 \mathrm{~min}$ of continuous exercise. The relative increases were similar to the results obtained in the present study, but the absolute values were $50 \%$ lower than ours. In addition, Krauss et $a l^{32}$ reported in 1993 very low absolute values, only $42 \%$ of the values in the present study. In comparison with both the present study and the study by Goss et $a l^{24}$ they found a much larger relative increase from $0.51 \pm 0.05$ to $0.83 \pm 0.06 \mathrm{litres} / \mathrm{min}$ that corresponded to $62 \%$. In that study no habituation was allowed and the final measurement after 6 weeks of exercise was done at almost the same time as the measurement in the present study (after 5.8 weeks). The lack of habituation could explain the differences in relative increases between studies. Kraus et $a l^{32}$ reported blood lactate values of $6.1 \pm 0.1 \mathrm{mmol} / 1($ mean $\pm \mathrm{SE})$ after the end of the exercise stress tests and found no changes during the period of training. This value is less than the $10.3 \pm 0.6 \mathrm{mmol} / 1$ found in the present study, but does still indicate a high relative intensity of exercise during the stress test.

The very low $\mathrm{VO}_{2}$-max values during wheelchair exercise found in the present study support data from other investigators ${ }^{33-36}$ and indicates that voluntary exercise with the upper body only allows for a small increase in $\mathrm{VO}_{2}$-max and probably is insufficient to maintain a high level of fitness in these individuals. Furthermore, the fact that considerably higher $\mathrm{VO}_{2}$ can be achieved during FES cycle exercise than during maximum voluntary arm exercise supports the expectation that electrical muscle stimulation may represent a useful therapeutic modality preventing inactivity associated illnesses in SCI individuals.

To summarize the different increases in maximal oxygen uptake rates over time in the various studies reported, the values are given in Figure 5. From the figure it is clear that the first $\mathrm{VO}_{2}$-max measurement was made later during training in the present study than in other studies. The first measurement was postponed to let the subjects adapt to the exercise and in order to secure measurements during exercise

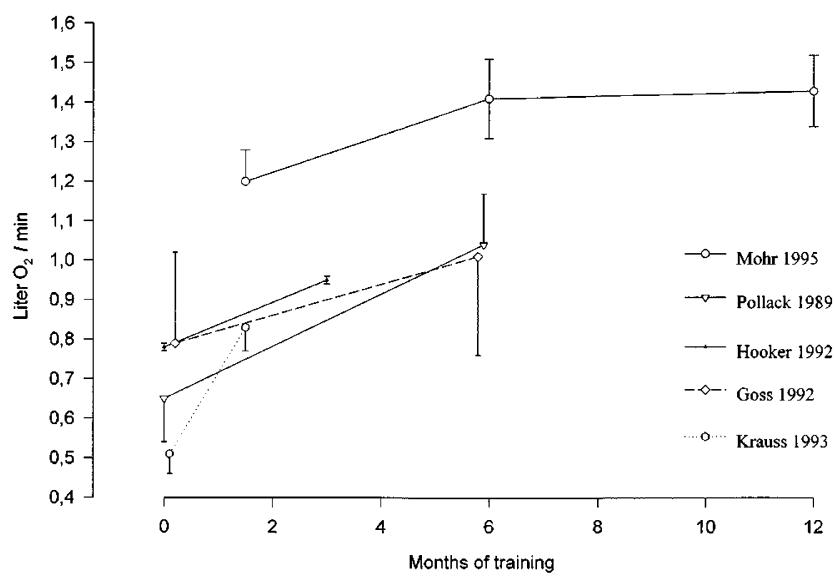

Figure 5 Maximal oxygen uptake found in different studies using training on the same equipment (REGYS ergometer) as in the present study

steady-state. In some of the studies with very low start values, these values could be due to lack of adaptation to the exercise and to test procedures used in the measurements of $\mathrm{VO}_{2}$-max. Furthermore, steady state was probably not reached during testing. ${ }^{29,32}$

None of the other studies mention the degree of voluntary upper body movement during the exercise stress test. Especially in paraplegics, some inevitable upper body movements took place during the stress tests also in the present study and such voluntary exercise will contribute to the measured $\mathrm{VO}_{2}$-max. However, these movements seem unavoidable during maximal effort and it is unlikely that $\mathrm{VO}_{2}$-max from all other reported studies only should represent FES exercise without any upper body movements. Furthermore, it should be noted that in the present study the tetraplegic individuals who performed almost no voluntary upper body exercise during the FES exercise had higher $\mathrm{VO}_{2}$-max values than did those who were paraplegic, indicating that upper body movements contribute only little to the overall $\mathrm{VO}_{2}$ measured during FES induced leg exercise.

Finally, one other possible reason for the differences in the reported $\mathrm{VO}_{2}$-max values could be a difference between the selection of the subjects. The subjects in the present study were highly motivated and entered the study because of their own interest and may therefore not represent the general SCI population in Denmark.

\section{Thigh girth}

A small but significant increase was seen in thigh circumference during the period of training. During the first 6 months of training the increase of the thigh circumference $20 \mathrm{~cm}$ above the patella edge was $0.9 \pm 0.2 \mathrm{~cm} \quad($ mean $\pm \mathrm{SE}), \quad P<0.05$ and after 12 months of training it was $1.8 \pm 0.3 \mathrm{~cm}$ (mean $\pm \mathrm{SE}$ ), $P<0.05$. This corresponded to increases of $3 \%$ and $5 \%$ respectively. No differences in the body weight of the 
subjects was observed before versus after the training period. Other investigators have reported an increase in circumference of the thigh after shorter periods of training. ${ }^{10,37}$ In one study an average increase of 5.3 centimetres was found after only 36 sessions of $15 \min ^{10}$ and another study reported a $5 \%$ increase after 8 weeks with 3 times training per week. ${ }^{37}$ However, a change in thigh circumference could also reflect an increase in the amount of fat tissue in the leg or a post exercise increase in muscle water, if the measurement was performed after exercise. ${ }^{15}$ Measurement of changes in thigh girth does not reveal which tissues are changing in mass. An increase in muscle mass may even take place in the absence of any change in circumference if it is accompanied by a decrease in fat mass. The method is therefore of limited value and should not have too much emphasis. A more direct approach to evaluate the muscle volume is the use of CT or MR images of the thigh.

\section{Muscle cross sectional area in the thigh}

Magnetic Resonance (MR) images were performed on nine patients. One paraplegic individual had an implanted anterior sacral root stimulator to control voiding of urine. Due to the presence of this device he could not enter the magnetic field and for his own safety, he had a CT scan performed instead. The images were all produced at the same level of the thigh before and after the training period. Five cross sectional images were made and all images made before training were compared with images at the same level made after the training period (Figure 6). A small increase in the thigh circumference measured by MRI of $5 \%$ was found $(P<0.05)$, corresponding to the small increase in the manually measured thigh circumference. No changes were noted in the cross sectional area of the femoral bone in response to

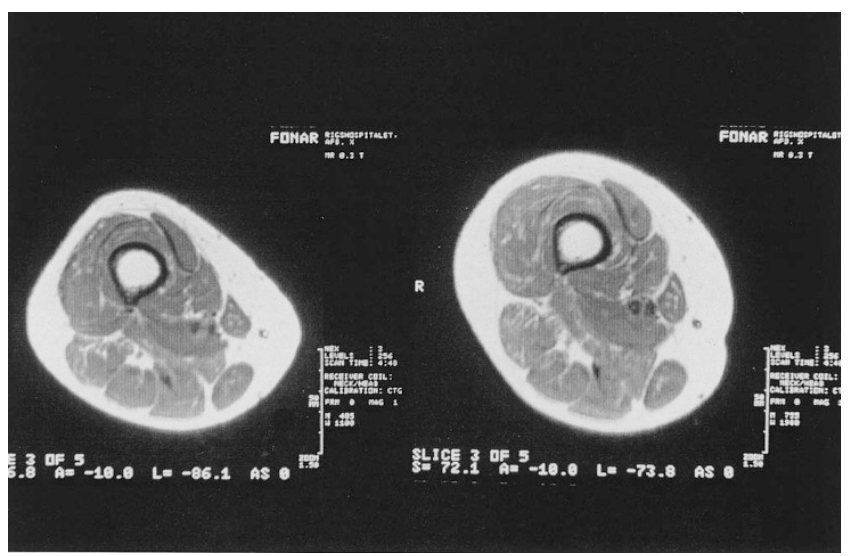

Figure 6 Cross sectional magnetic resonance image (MR) of the thigh, before (left) and after (right) the training period in the same subject. In this subject, a change is evident, and the average muscle area increase in all subjects was $12 \%$ training. The area of the subfacial soft tissue showed a significant increase from $89.9 \pm 10.2 \mathrm{~cm}^{2}($ mean \pm SE) to $100.8 \pm 9.5$, corresponding to a change of $12 \%$ $(P<0.05)$. From the images performed, it was not possible to define borders of individual muscle groups in the thigh. Furthermore, the increase in estimated overall area of muscle may not accurately reflect changes in muscle fibre mass as changes may take place in amount of interstitial tissue which are not accounted for (see below).

No earlier studies have reported the use of MR Imaging to evaluate muscle growth in SCI humans after training with FES cycling, but recent studies have used computer tomography (CT) to evaluate the increase in muscle area in the thigh after 3 months of FES training. ${ }^{27,38-41}$ After 3 months with the same amount of training as in the present study Sloan et al ${ }^{40}$ found an increase of $9 \%$ in the quadriceps, whereas no change was seen in the hamstrings. Block et $a l^{39}$ found a significant increase in cross sectional area of the anterior muscle group of the thigh after 6 weeks of training whereas Bremner et $a l^{41}$ found no change and explained this by a small sample size. Pacy et al used qualitative CT in the evaluation of muscle volume. ${ }^{27}$ They studied four patients who exercised five times 15 min per week for 10 weeks with electrically stimulated resistance training of the quadriceps followed by 32 weeks of electrically stimulated cycle training five times 15 min per week. Assuming that the intensity of the scan within each pixel is directly related to the muscle to fat ratio they were able to take into account a possible change in the structure within the muscle. During the 32 weeks of electrically stimulated cycle exercise no increase in muscle mass was found, but a large increase was seen during the resistance training period before the cycle period. Furthermore, muscle content relative to fat content increased as a result of the training. The lack of increase in the cycle training period could be due to the fact that a large increase had already occurred during the preceding resistance training exercise. The finding of changed muscle composition ${ }^{27}$ is in accordance with our biopsy finding of an increase in the relative amount of contractile proteins and a decrease in connective tissue and fat, see below. In support of an increase in muscle volume, Pacy et al also found an increase of $28 \%$ in rate of protein synthesis in the quadriceps muscle.

One other study has used MR Imaging to evaluate muscle growth in SCI humans. ${ }^{42}$ In contrast to the present study, transcutaneous needle stimulation was used and no resistance was applied. The stimulation was more intensive than in the present study, ie up to $60 \mathrm{~min}$, three times daily, for up to 6 months. The cross sectional areas were individually evaluated for each single muscle in the thigh. The increase in cross sectional area for the isolated muscles was much higher (increases from 20 to $100 \%$ in the biceps femoris muscle) than the increase in estimated total muscle cross sectional area in the thigh in the present 


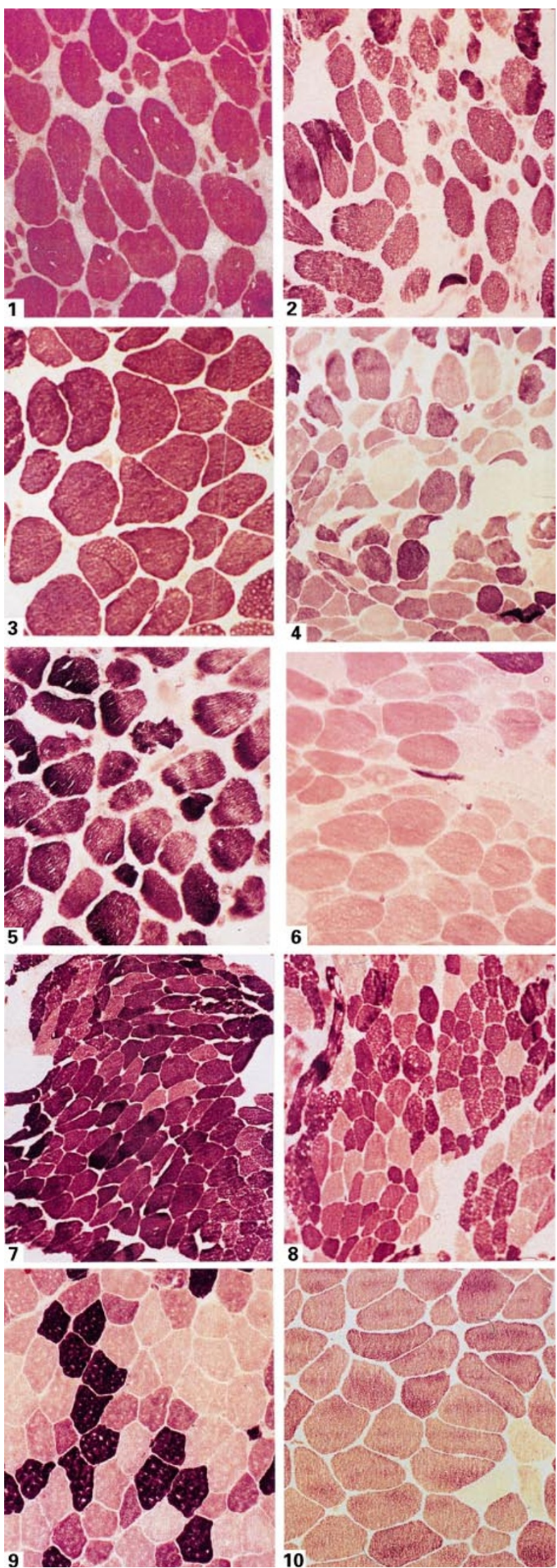

study. The difference between studies may reflect that muscle growth was underestimated in the present study (see below) but may also be due to the longer stimulation duration used in the other study. In any case, it is interesting that contractions in spite of absence of added resistance, induced a substantial increase in muscle cross sectional area. ${ }^{42}$

\section{Muscular microstructure}

A great inter-individual variation was found in the microstructure of the muscle biopsies obtained in the SCI individuals before the training. The structure of the muscle showed to a variable degree atrophy of the fibres, altered structure of the fibres and large amounts of perimysial tissue (Figure 7).

In the biopsies with the most abnormal appearance before training, the shape of the fibres was mostly round and a varying number of very small cells $\left(<200 \mu \mathrm{m}^{2}\right)$ was seen. The perimysial tissue consists of loose connective tissue and adipose tissue. There may be a relationship between the duration of injury and the degree of abnormality in structure because the structure was most deteriorated in subject nos. 1 and 2, who were studied 19 and 20 years after their injury respectively. However, the structure was surprisingly normal in the subject with the longest lasting SCI (no. 8,24 years). The fact that some SCI subjects have more frequent spasms in the paralysed muscles than others might explain differences in muscle appearance between subjects. However, the quality and quantity of spasms during the day cannot be measured and subjective evaluation would not be accurate and was therefore not recorded in the present study.

A relationship between performance and muscle structure was present, since the two subjects (nos. 1 and 2) with the most deteriorated structure had the lowest performance level in the beginning of the study and the slowest increase in performance during the training period. In the subjects demonstrating the most abnormal appearance of the muscle tissue before the training, the biopsies taken after training were surprisingly normal. This indicates reversibility of the disuse changes, even after more than 20 years without normal function of the muscle (Figure 8). No significant changes in the fibre areas were observed for any of the fibre types separately or for all fibres together. The average fibre area was $2330 \pm 385 \mu \mathrm{m}^{2}$, $2930 \pm 368 \mu \mathrm{m}^{2}$ and $2759 \pm 202 \mu \mathrm{m}^{2}$ (mean $\left.\pm \mathrm{SE}\right)$ before training, after 6 months and after 12 months, respectively. Note, however, that fibres with an area

Figure 7 The structure of muscle tissue in the $10 \mathrm{SCI}$ subjects before the training. ATPase stains of muscle sections after preincubation at $\mathrm{pH} 4.6$, or in one case (bottom right) at $\mathrm{pH}$ 10.3. The sections illustrate the large variability in structure between the paralysed muscles of SCI individuals. The numbers given correspond to the numbers in Table 1 


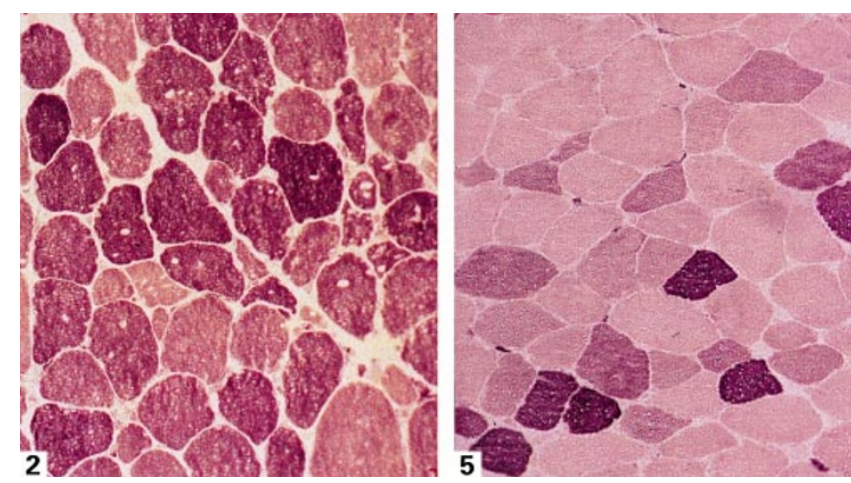

Figure 8 The structure of the muscle tissue after training. Biopsies from subject no 2, 20 years post injury (left) and subject no 5, 8 years post injury (right). Note the normalization of the structure after the training in both subjects as compared to Figure 7

below $200 \mu \mathrm{m}^{2}$ were not taken into account because they could not with certainty be distinguished from artefacts. The fact that the number of such fibres decreased markedly with training indicates that they may really be fibres and that their size increased with training.

Few studies are available on the structure of muscle tissue in SCI humans and the descriptions reveal conflicting results. Scelsi and coworkers ${ }^{43}$ described marked fibre atrophy with a decrease in fibre diameter, accumulation of lipid and interstitial fibrosis and alterations in the microcirculation in patients less than two years after their SCI. This is in accordance with the findings in some of our subjects. In contrast, Round and coworkers ${ }^{44}$ described generally unremarkable Haematoxylin-Eosin stained sections, showing well-formed and regular muscle fibres in seven males 1 to 9 years after SCI. This is in accordance with the findings in several of our subjects. However, the fibre size and amount of interstitial tissue was not specifically described. ${ }^{44}$ In two other studies on muscle fibre type changes no description of the microstructure in the biopsies was given but the photos of histological sections shown in the papers appeared almost normal. ${ }^{45,46}$ Greve et $a l^{47}$ performed a study with 90 days of electrical stimulation and described biopsy data before and after the training. In four patients, 1 to 2 years after injury, they found atrophy of the fibres with a subnormal fibre diameter but the published photograph of the sections showed an almost normal structure with minor increases in the interfibrillar tissue content. The latter parameter was not described by the authors but can be evaluated from the illustrations presented in the paper. After the training period the interfibrillar tissue had disappeared. The accumulation of interfibrillar tissue demonstrated in muscle a few years after $\mathrm{SCI}^{47}$ may represent an early stage of the derangement fully developed in some of our subjects with a long (more than 10 years) duration of injury. The large variation in time after injury could, to a large extent, explain the striking difference in the histological muscle structure between our subjects before the training and also the differences between the present and the above mentioned studies, which included only subjects with more recent SCI.

Fibre types, MHC analysis on homogenates

In muscle biopsies obtained before training the $\mathrm{MHC}$ isoform IIB was dominating $(63.0 \pm 7.3 \%$ of total $)$ whereas $\mathrm{MHC}$ isoform IIA only accounted for $32.6 \pm 7.0 \%$ of total MHC. After 1 year of training this picture was reversed, with samples only containing $31.8 \pm 6.4 \%$ MHC type IIB and with a corresponding increase to $61.1 \pm 6.8 \%$ for $\mathrm{MHC}$ isoform IIA. No changes were observed in the amount of MHC isoform I $(4.4 \pm 2.0 \%$ and $7.1 \pm 2.4 \%$, before and after training, respectively) (Figure 9).

The traditional determination of muscle fibre types based on histochemistry after preincubation at different $\mathrm{pH}$ could have disadvantages concerning accuracy of the results, especially in atrophied muscles with many small fibres. The distribution of the different isoforms of $\mathrm{MHC}$ according to their electrophoretic mobility gives the quantitative relationship between the MHC isoforms more directly. Furthermore, this method gives the distribution of the contractile proteins in a muscle sample irrespectively of the size of the muscle cells. Thus, with this method the specific problems inherent in distinction between artefacts and atrophied fibres before training can be avoided, since all contractile material will be measured, even the content in very small cells that

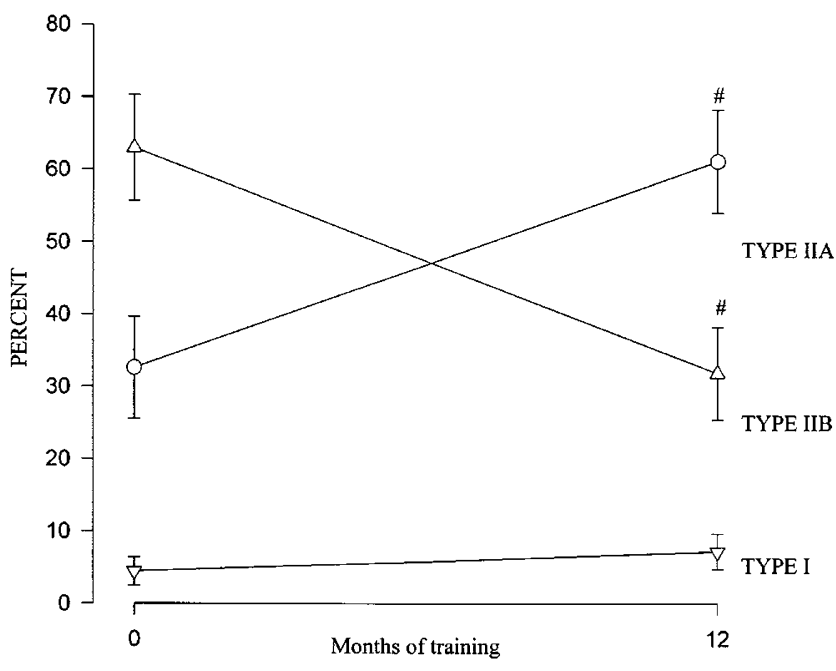

Figure 9 Distribution of myosin heavy chain (MHC) isoforms in homogenates of muscle biopsies from SCI subjects trained by FES cycling. Values are mean \pm SE and \# indicates difference from before training 
otherwise would not have been accounted for. The more atrophied the muscle the smaller would the agreement between MHC and histochemistry evaluation be expected to be. After SCI, changes due to disuse have been found in both animals and humans. Atrophy of all paralysed muscle fibres and a conversion from slow to fast fibre type have been demonstrated by histochemistry after cordotomy in rats. ${ }^{48}$ Studies have indicated that a similar change takes place after SCI in humans. ${ }^{43,44,46,49}$ In subjects studied within the first month after damage of the spinal cord an almost normal distribution of fibres was found, whereas very high percentages of type IIB fibres and low percentages of type I fibres have been demonstrated in SCI subjects $9-10$ and 17 months, respectively after injury. ${ }^{43,49}$ It was suggested that the findings might reflect a fibre transformation from slow twitch type I to fast twitch type IIB in response to spasticity in the paralysed muscles. ${ }^{49}$ In studies of SCI individuals after longer periods in the injured state, the percentage of type I fibres was smallest in the individuals with the longest duration of injury, with a dominance of type IIB fibres in subjects more than 2 years after SCI. ${ }^{44,46}$ The muscle fibre type distribution in the muscles above the level of the spinal cord lesion (deltoid muscle in paraplegics) has been found to be normal even several years after injury. ${ }^{46}$ However, only indirect evidence of fibre type transformation after SCI exists, since no longitudinal studies have been performed in SCI humans.

The subjects in the present study were more than three years post injury, indicating that the initial changes suggested by the cross sectional studies should have taken place. ${ }^{43,44,46,49}$ The subjects in the present study were $12.5 \pm 2.0$ years (mean $\pm \mathrm{SE}$ ), range $3-24$ years after injury at the start of the exercise. Corresponding to previous findings in SCI humans a high percentage of $\mathrm{MHC}$ isoform IIB and very little MHC isoform I in muscle were seen in our subjects before initiation of training.

The reversibility of the disuse changes in paralysed muscle by means of FES has previously been studied in humans. ${ }^{12,45,47}$ In the first five of the subjects included in the present study we have previously reported a transformation of $\mathrm{MHC}$ in single fibres. ${ }^{12}$ The transformation from isoform IIB to isoform IIA was a continuous process throughout the full time of training (Figure 10). ${ }^{12}$ In the single fibres, the 12 months of FES training induced a switch from a mixed pool of fibres expressing only MHC IIA, only IIB or co-expressing IIA and IIB to a uniform pool of fibres expressing only $\mathrm{MHC}$ IIA. $^{12}$

In another study 24 weeks of $20 \mathrm{~Hz}$ stimulation ( $5 \mathrm{~s}$ on $-5 \mathrm{~s}$ off) of tibialis anterior muscle in spinal cord injured subjects for up to $8 \mathrm{~h}$ a day increased the content of fibres classified as type $I$ in the stimulated $(25 \pm 10 \%)$ compared to the unstimulated $(14 \pm 8 \%$, range $1-49 \%)$ tibialis muscle. ${ }^{45}$ In contrast, no increase in type I was noted in a recent study using smaller amounts of stimulation, ie, two times $30 \mathrm{~min}$ of $20-30 \mathrm{~Hz}$ stimulation $(5 \mathrm{~s}$ on $-10 \mathrm{~s}$ off) of the quadriceps muscle for 90 consecutive days (13 weeks). In that study only an increase in the percentage of type IIA fibres was demonstrated. ${ }^{47}$ Thus, in contrast to the mentioned findings after prolonged stimulation at $20 \mathrm{~Hz}^{45}$ stimulation at frequencies of $20-30 \mathrm{~Hz}$ for only $1 \mathrm{~h}$ (real duration of stimulation, however, which was only one third of the time corresponding to $20 \mathrm{~min}$ per day during 13 weeks, did not increase the number of histochemically determined type I fibres in humans. ${ }^{47}$ These findings suggest that the total number of impulses given may be important for the fibre type transformation.

In addition, it cannot be ruled out that the fibre type transformation in humans also depends on the stimulation frequency given to the muscle. The present findings were comparable with findings in the study described above by Greve et $a l^{47}$ even though a lower number of electrical impulses per day was given in our study. The training was $30 \mathrm{~min}$ three times a week and the quadriceps was only stimulated one third of this time, resulting in only $10 \mathrm{~min}$ of stimulation at $30 \mathrm{~Hz}$ three times a week, corresponding to approximately 4 min per day.

The lower number of impulses administered per day in the present study compared to the previous human studies ${ }^{45,47}$ was, regarding total number of stimuli, not fully counterbalanced by the fact that electrical stimulation was repeated for a longer period of time (52 versus $24^{45}$ and $13^{47}$ weeks). Interestingly however, the time course presented in the current study shows that fibre type conversion may continue throughout a whole year of intermittent stimulation.

The view that the overall number of electrical stimuli to the muscle is important for fibre type adaptation is also supported by the finding that $10 \mathrm{~Hz}$ stimulation of the anterior tibialis muscle of SCI individuals for $72 \mathrm{~min}$ a day for only 4 weeks did not result in histochemically detectable changes in muscle fibres. ${ }^{50}$ However, as stated, it cannot be ruled out that in addition to the total number of impulses, the fibre type transformation in humans is dependent on the stimulation frequency. This influence of frequency on the fibre type transformation is likely to be species-specific in animals, ${ }^{51,52}$ but evidence for the influence of frequency seems to be limited in humans.

The view that resistance to fatigue may be improved by electrical stimulation is supported by interesting experiments in humans in which latissimus dorsi muscle was transposed and electrically paced to compensate for impaired cardiac performance. ${ }^{53}$ It was found that the muscle was only able to retain shortening in a pulse synchronous manner after an adaptation period of 3 weeks. In these experiments fibre type composition was not determined but it is likely that the fibre types shifted towards more oxidative and less fatiguable ones. ${ }^{54}$ 
Citrate synthase activity in muscle tissue

The muscle citrate synthase (CS) activity was measured as an indicator of the capacity of mitochondrial oxidation (Krebs Cycle). The CS activity was determined in biopsies taken before and after 3 and 6 months and after 1 year of training. From a basic value of $12.3 \pm 1.4 \mathrm{mmol} / \mathrm{kg} \quad \mathrm{d} . \mathrm{w} . / \mathrm{min}$ the activity increased after 3 months of training to $24.8 \pm 2.2$ $(P<0.05)$, and remained unchanged $(P>0.05)$ at this level for the rest of the training period. The initial activity level was in the range of what has previously been reported in sedentary healthy man and the increase found was in accordance with previously reported data from studies on trained individuals. ${ }^{55,56}$

The adaptability of oxidative enzymes in response to training is local in nature ${ }^{57}$ and in our study increases were observed in biopsies from stimulated muscles. In animals as well as in humans it has previously been shown that long term electrical stimulation increases CS activity. ${ }^{55,58}$ In able-bodied humans increases were only approximately $30 \%$ after 6 weeks of $8 \mathrm{~Hz}$ stimulation in quadriceps for $3 \mathrm{~h}$ per day. The increase in CS occurred in our study quite rapidly compared to other adaptations to exercise, corresponding to what is seen during training of extremely inactive bedridden able-bodied subjects. ${ }^{59}$ Studies on electrically stimulated $(10 \mathrm{~Hz}, 8 \mathrm{~h} /$ day $)$ rat fast twitch muscle also showed a steep increase of $36 \%$ within the first 10 to 20 days of stimulation but thereafter an increase of only $26 \%$ until day 30 to 40 where a plateau was reached. ${ }^{60}$ This corresponded with the fact that a plateau was reached after 3 months in the present study.

It is interesting to note that for CS the adaptation was completed while conversion of fibres from types thought to be predominantly glycolytic to types thought to be more oxidative was still proceeding (Figure 10). Furthermore, muscle oxidative capacity, as indicated by CS activity, increased to a greater extent than FES induced whole body maximum oxygen uptake (Figures 4 and 10). This finding agrees with studies exploiting the effect of endurance training and detraining in the healthy man. ${ }^{59}$ From these studies it could be concluded that maximal oxygen uptake in healthy man is limited by cardiopulmonary capacity rather than by peripheral skeletal muscle oxidative capacity. In the present study muscle mass, as indicated by thigh circumference measurements, probably continued to increase after $\mathrm{CS}$ concentration had reached a plateau. However, the increase was not accompanied by an increase in maximum oxygen uptake during the last 6 months of training. So at the end of training cardiopulmonary capacity rather than muscle oxidative capacity probably limited performance in SCI subjects, as also demonstrated in able-bodied man.

\section{Conclusions}

The present study has shown that use of FES training in SCI subjects is possible for a period as long as 1
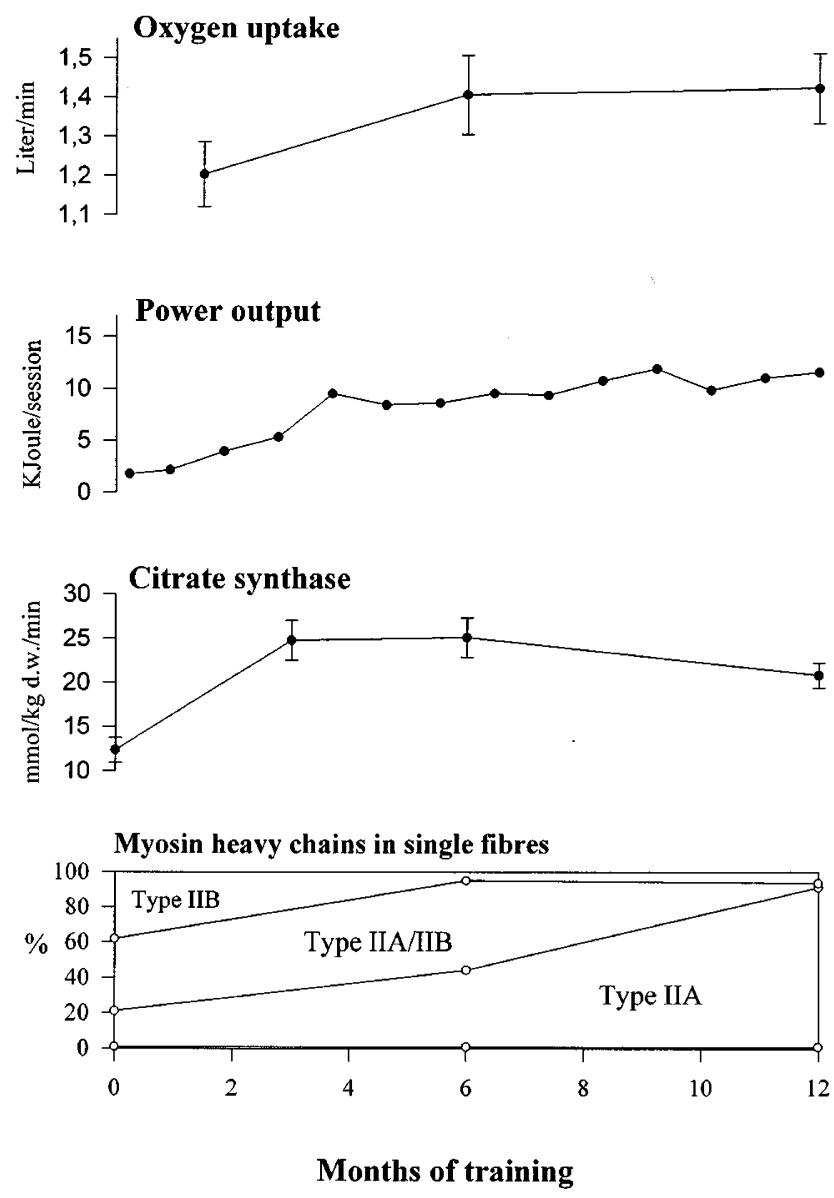

Figure 10 Time course of adaptations seen over 12 months of FES training in SCI subjects. The figure of myosin heavy chains is adapted from ref ${ }^{12}$

year without any physical drawbacks. This makes it most likely that FES training can be incorporated into the daily life of SCI individuals. The benefits of this training can thereby be sustained throughout the lifetime of the individuals.

The study has furthermore shown that electrically induced cycle training for 1 year can reverse several of the inactivity associated changes seen after SCI. The subjects increased their work performance more than sixfold measured as power output during the single exercise bout (Figure 10). An increase was seen very early in the training period (weeks) and power output levelled off after the first 6 months of training (Figure 10). The increase in power output was accompanied by an increase in maximal oxygen uptake of $23 \%$, which also plateaued during the last 6 months of training (Figure 10).

Atrophy of the muscles in the lower extremities was evident in the subjects before training. Electrical stimulation increased the total amount as well as altered the characteristics of the muscle. After 1 year of training thigh muscle cross sectional area had 
increased $12 \%$ and growth of stimulated muscle also appeared from the histological section of the muscles. The distribution of contractile protein (myosin heavy chain (MHC) isoforms) in the muscle was determined. Before training the majority of the $\mathrm{MHC}$ was isoform IIB fibres as also found in other studies of SCI individuals years after injury, evaluated by histochemistry. A fibre type transformation towards the more fatigue resistant MHC isoform IIA was seen over time with an almost total shift after 1 year (Figure 10). Before training only very little MHC isoform I was found and this did not increase in response to training. The lack of transformation to this fibre type could be due to the stimulation parameters used, or to the fact that the overall number of stimuli or the work performed was too small to elicit such an adaptation. Little is known about which parameters (frequency or intensity of stimulation, number of stimuli or mechanical load) are responsible for the direction of the fibre type transformation and further studies need to be done in that area.

Assuming a resting metabolic rate of $0.251 / \mathrm{min}$ for the rest of the body, maximal oxygen consumption in electrically stimulated muscle increased $29 \%$ during training. This increase was much smaller than the increase in muscle oxidative capacity as judged from changes in muscle mass, MHC isoforms and CS activity. It follows that the adaptations in muscle may well account for the training induced increase in maximal oxygen uptake and performance. These findings indicate that at the end of training cardiopulmonary capacity rather than peripheral oxidative capacity limited oxygen uptake. This conclusion is supported by the fact that during the last 6 months of training maximal oxygen uptake was constant in the face of increasing muscle mass and ongoing type IIB to type IIA fibre conversion $^{12}$ (Figure 10).

In healthy man increases in maximal oxygen uptake with training are due to increases in maximal cardiac output. ${ }^{59}$ However, it seems likely that upon spinal cord injury overall oxidative capacity in paralysed muscle deteriorates relatively more than cardiopulmonary function and that, accordingly, maximum oxygen uptake can be improved by restoration of muscle. Furthermore, maximal heart rates obtained during exercise is approximately 120 beats per minute in tetraplegics and 150 in paraplegics and thus lower than seen in able-bodied subjects. This is compatible with the view that compared with endurance training in able-bodied subjects, FES cycle training of SCI subjects results in a relatively higher stimulus to adaptation in contracting muscle than in the heart.

The fact that it seems possible to permanently incorporate regular FES training in the daily living of SCI subjects encourages further studies regarding the possible benefits associated with this treatment. It can be expected that other inactivity associated disorders (eg hyperlipidemia, osteoporosis, pulmonary infections, glucose intolerance and pressure sores) may be counteracted by FES training.

\section{Acknowledgements}

We thank Per Tornøe, Physiotherapist (PT) for his excellent assistance with the FES training. This study was supported by grants from the Nat Soc of Polio and Accident Victims, the Danish Medical Research Council (Jnr. SSF 12-9360), the Danish National Research Foundation (504-14), The Hamilton Foundation, Danish Hospital Foundation for Medical Research (Region of Copenhagen, The Faroe Islands and Greenland), Idraettens Forskningsråd, the Danish Heart Foundation, the Foundation of $\mathbf{J}$ and $\mathrm{O}$ Madsen, the Danish Medical Association Research Foundation and, Team Denmark.

\section{References}

1 Jackson RW, Fredrickson A. Sports for the physically disabled. The 1976 Olympiad (Toronto). American Journal of Sports Medicine 1979; 7(5): 293-296.

2 Geisler WO, Jousse AT, Wynne-Jones M, Breithaupt D. Survival in traumatic spinal cord injury. Paraplegia 1983; 21: $364-373$.

3 Biering-Sorensen E, Pedersen V, Clausen S. Epidemiology of spinal cord lesions in Denmark. Paraplegia 1990; 28: 105-118.

4 Harrison CL, Dijkers M. Spinal cord injury surveillance in the United States: an overview. Paraplegia 1991; 29: 233 - 246.

5 Le CT, Price M. Survival from spinal cord injury. Journal of Chronic Diseases 1982; 35: $487-492$.

6 Bauman WA et al. Coronary artery disease: metabolic risk factors and latent disease in individuals with paraplegia. Mount Sinai Journal of Medicine 1992; 59: 163-168.

7 DeVivo MJ, Black KJ, Stover SL. Causes of death during the first 12 years after spinal cord injury. Archives of Physical Medicine \& Rehabilitation 1993; 74(3): 248-254.

8 LaPorte RE et al. The spectrum of physical activity, cardiovascular disease and health: an epidemiologic perspective. American Journal of Epidemiology 1984; 120: 507-517.

9 Wicks JR, Oldridge NB, Cameron BJ, Jones NL. Arm cranking and wheelchair ergometry in elite spinal cord-injured athletes. Med Sci Sports Exerc 1983; 15: 224 - 231.

10 Ragnarsson KT et al. Clinical evaluation of computerized functional electrical stimulation after spinal cord injury: a multicenter pilot study. Archives of Physical Medicine \& Rehabilitation 1988; 69: 672-677.

11 Kjaer $\mathrm{M}$ et al. Cardiovascular and ventilatory responses to electrically induced cycling with complete epidural anaesthesia in humans. Acta Physiologica Scandinavica 1994; 151(2): 199-207.

12 Andersen JL et al. Myosin heavy chain isoform transformation in single fibres from m.vastus lateralis in spinal cord injured individuals: effects of long-term functional electrical stimulation (FES). Pflugers Arch-Eur J Physiol 1996; 431: 513-518.

13 Kjaer $\mathrm{M}$ et al. Hormonal, metabolic and cardiovascular responses to static exercise in humans: influence of epidural anesthesia. American Journal of Physiology 1991; 261: E214E220.

14 Secher NH, Ruberg-Larsen N, Binkhorst RA, Bonde-Petersen F. Maximal oxygen uptake during arm cranking and combined arm plus leg exercise. Journal of Applied Physiology 1974; 36(5): $515-$ 518.

15 Komulainen J. Muscle water content and serum creatine kinase in exercise-induced damage. 1994; LIKES Research Centre for Physical Culture and Health; Thesis.

16 Bergström J. Muscle electrolytes in men. Scandinavian Journal of Clinical \& Laboratory Investigation - Supplement 1962; 68.

17 Brooke MH, Kaiser KK. Muscle fiber types: how many and what kind? Archives of Neurology 1970; 23(4): 369-379.

18 Fry AC. Allemeier CA, Staron RS. Correlation between percentage fiber type area and myosin heavy chain content in human skeletal muscle. European Journal of Applied Physiology \& Occupational Physiology 1994; 68(3): 246-251. 
19 Klitgaard $\mathrm{H}$ et al. Function, morphology and protein expression of ageing skeletal muscle: a cross-sectional study of elderly men with different training backgrounds. Acta Physiologica Scandinavica 1990; 140: $41-54$.

20 Passonneau JV, Lowry OH. Enzymatic Analysis, A Practical Guide. Totowa NJ: Humana Press; 1993.

21 Glaser RM, Figoni SF, Couch W et al. Effect of increased maximum current during electrical stimulation leg cycle ergometry. [Abstract] Med Sci Sports Exerc 1994; 26: (5, Supplement) S 111 .

22 Faghri PD, Glaser RM, Figoni SF. Functional electrical stimulation leg cycle ergometer exercise: training effects on cardiorespiratory responses of spinal cord injured subjects at rest and during submaximal exercise. Archives of Physical Medicine \& Rehabilitation 1992; 73: 1085 - 1093.

23 Hooker SP et al. Physiologic effects of electrical stimulation leg cycle exercise training in spinal cord injured persons. Archives of Physical Medicine \& Rehabilitation 1992; 73: 470476.

24 Goss FL, McDermott A, Robertson RJ. Changes in peak oxygen uptake following computerized functional electrical stimulation in the spinal cord injured. Research Quarterly For Exercise \& Sport 1992; 63: 76-79.

25 Taaffe DR et al. Effect of sustained resistance training on basal metabolic rate in older women. Journal of the American Geriatrics Society 1995; 43(5): 465-471.

26 Arnold PB et al. Functional electric stimulation: its efficacy and safety in improving pulmonary function and musculoskeletal fitness. Archives of Physical Medicine \& Rehabilitation 1992; 73: 665-668.

27 Pacy PJ et al. Muscle and bone in paraplegic patients and the effect of functional electrical stimulation. Clinical Science 1988; 75: $481-487$

28 Pollack SF et al. Aerobic training effects of electrically induced lower extremity exercises in spinal cord injured people [see comments]. Archives of Physical Medicine \& Rehabilitation 1989; 70: $214-219$

29 Petrofsky JS, Stacy R. The effect of training on endurance and the cardiovascular responses of individuals with paraplegia during dynamic exercise induced by functional electrical stimulation. European Journal of Applied Physiology \& Occupational Physiology 1992; 64: 487-492.

30 Faghri PD et al. Feasibility of using two FNS exercise modes for spinal cord injured patients. Clin Kinesiol 1989; 43: 62-68.

31 Astrand PO, Rodahl K, Van Dalen DB, editor. Textbook of work physiology., 3rd ed. New York: McGraw-Hill Book Company; 1986.

32 Krauss JC et al. Effects of electrical stimulation and upper body training after spinal cord injury. Med Sci Sports Exerc 1993; 25: $1054-1061$

33 Drory $\mathrm{Y}$ et al. Arm crank ergometry in chronic spinal cord injured patients. Archives of Physical Medicine \& Rehabilitation 1990; 71: $389-392$.

34 Di Carlo SE. Effect of arm ergometry training on wheelchair propulsion endurance of individuals with quadriplegia. Physical Therapy 1988; 68: 40-44.

35 Hjeltnes N. Cardiorespiratory capacity in tetra- and paraplegia shortly after injury. Scandinavian Journal of Rehabilitation Medicine 1986; 18: $65-70$.

36 Coutts KD. Heart rates of participants in wheelchair sports. Parapalegia 1988; 26: $43-49$.

37 Phillips CA, Danopulos D, Kezdi P, Hendershot D. Muscular, respiratory and cardiovascular responses of quadriplegic persons to an F.E.S. bicycle ergometer conditioning program. International Journal of Rehabilitation Research-Internationale Zeitschrift Fur Rehabilitationsforschung-Revue Internationale De Recherches De Readaptation 1989; 12: $147-157$.

38 Ragnarsson KT. Physiologic effects of functional electrical stimulation-induced exercises in spinal cord-injured individuals. Clinical Orthopaedics \& Related Research 1988; 233: 53 - 63.

39 Block JE et al. Electrically-stimulated muscle hypertrophy in paraplegia: assessment by quantitative CT. Journal of Computer Assisted Tomography 1989; 13: $852-854$.
40 Sloan KE et al. Musculoskeletal effects of an electrical stimulation induced cycling programme in the spinal injured. Paraplegia 1994; 32: 407 - 415.

41 Bremner LA et al. A clinical exercise system for paraplegics using functional electrical stimulation. Paraplegia 1992; 30: 647 - 655.

42 Kagaya H, Shimada Y, Sato K, Sato M. Changes in muscle force following therapeutic electrical stimulation in patients with complete paraplegia. Paraplegia 1996; 34(1): 24-29.

43 Scelsi R et al. Muscle fiber type morphology and distribution in paraplegic patients with traumatic cord lesion. Histochemical and ultrastructural aspects of rectus femoris muscle. Acta Neuropathologica 1982; 57(4): 243-248.

44 Round JM, Barr FM, Moffat B, Jones DA. Fibre areas and histochemical fibre types in the quadriceps muscle of paraplegic subjects. Journal of the Neurological Sciences 1993; 116: $207-$ 211 .

45 Martin TP, Stein RB, Hoeppner PH, Reid DC. Influence of electrical stimulation on the morphological and metabolic properties of paralyzed muscle. Journal of Applied Physiology 1992; 72: 1401 - 1406.

46 Grimby G, Broberg C, Krotkiewska I, Krotkiewski M. Muscle fiber composition in patients with traumatic cord lesion. Scandinavian Journal of Rehabilitation Medicine 1976; 8: 37 - 42 .

47 Greve JM et al. Functional electrical stimulation (FES): muscle histochemical analysis. Paraplegia 1993; 31: 764-770.

48 Lieber RL, Fridën JO, Hargens AR, Feringa ER. Long-term effects of spinal cord transection on fast and slow rat skeletal muscle. II. Morphometric properties. Experimental Neurology 1986; 91: $435-448$

49 Lotta $\mathrm{S}$ et al. Morphometric and neurophysiological analysis of skeletal muscle in paraplegic patients with traumatic cord lesion. Paraplegia 1991; 29: 247-252.

50 Rochester L, Barron LJ, Chandler CS et al. Influence of electrical stimulation on contractile and histochemical properties of tibialis anterior muscle in paraplegic human subjects. [Abstract] Journal of Physiology 1992; 452: 278.

51 Kirschbaum BJ, Heilig A, Hartner KT, Pette D. Electrostimulation-induced fast-to-slow transitions of myosin light and heavy chains in rabbit fast-twitch muscle at the mRNA level. Febs Letters 1989; 243: $123-126$.

52 Kirschbaum BJ et al. Rapid and reversible changes in myosin heavy chain expression in response to increased neuromuscular activity of rat fast-twitch muscle. Febs Letters 1990; 268: 75 - 78 .

53 Magovern GJ. Introduction to the history and development of skeletal muscle plasticity and its clinical application to cardiomyoplasty and skeletal muscle ventricle. Seminars in Thoracic \& Cardiovascular Surgery 1991; 3: 95-97.

54 Magovern GJ et al. Paced latissimus dorsi used for dynamic cardiomyoplasty of left ventricular aneurysms. Annals of Thoracic Surgery 1987; 44: 379-388.

55 Gauthier JM et al. Electrical stimulation-induced changes in skeletal muscle enzymes of men and women. Med Sci Sports Exerc 1992; 24: 1252 - 1256.

56 Schantz PG, Henriksson J. Enzyme levels of the NADH shuttle systems: measurements in isolated muscle fibres from humans of differing physical activity. Acta Physiologica Scandinavica 1987; 129: $505-515$.

57 Saltin B, Gollnick PD. Handbook of Physiology - Skeletal Muscle. Bethesta, MD, USA: American Physiology Society. 1983; 10, skeletal muscle adaptability: significance for metabolism and performance. pp. $555-631$.

58 Hudlicka $\mathrm{O}$ et al. The effect of long-term stimulation of fast muscles on their blood flow, metabolism and ability to withstand fatigue. Pflugers Archiv-European Journal of Physiology 1977; 369(2): $141-149$

59 Henriksson J, Reitman JS. Time course of changes in human skeletal muscle succinate dehydrogenase and cytochrome oxidase activities and maximal oxygen uptake with physical activity and inactivity. Acta Physiologica Scandinavica 1977; 99(1): $91-97$

60 Etgen GJ, Farrar RP, Ivy JL. Effect of chronic electric stimulation fatigue on GLUT-4 protein content in fast-twitch muscle. American Journal of Physical Medicine 1993; 264: 816-819. 